\title{
TI.53.1
}

\section{InCommon Federation Participant Domain Use Policy-v1.0}

- PDF: TI.53.1-InCommon Federation Participant Domain Use Policy-v1.0.pdf

- Text: TI.53.1-InCommon Federation Participant Domain Use Policy.txt

More Information

\begin{tabular}{|c|c|}
\hline Repository ID & TI.53.1 \\
\hline Persistent URL & http://doi.org/10.26869/TI.53.1 \\
\hline Title & InCommon Federation Participant Domain Use Policy-v1.0 \\
\hline Authors & $\begin{array}{l}\text { Nicholas Roy, The InCommon Registration Authority Team, The InCommon } \\
\text { Operations Team }\end{array}$ \\
\hline Sponsor & Ann West \\
\hline \multicolumn{2}{|l|}{ Review } \\
\hline Status & Preserve \\
\hline Publish Date & November 3, 2017 \\
\hline DOI & $10.26869 / \mathrm{TI} .53 .1$ \\
\hline \multicolumn{2}{|l|}{ Signature } \\
\hline \multicolumn{2}{|l|}{ Deprecated } \\
\hline Future Review & December 1, 2019 \\
\hline Supersedes & none \\
\hline \multicolumn{2}{|l|}{ Format } \\
\hline \multicolumn{2}{|l|}{ Related Docs } \\
\hline \multicolumn{2}{|l|}{ Development Location } \\
\hline \multicolumn{2}{|l|}{ IP Framework } \\
\hline Subject Tags & federation metadata trust dns \\
\hline Notes & \\
\hline
\end{tabular}

